\title{
Surgical Reintervention After Failed Antireflux Surgery: A Systematic Review of the Literature
}

\author{
Edgar J. B. Furnée • Werner A. Draaisma • \\ Ivo A. M. J. Broeders • Hein G. Gooszen
}

Received: 29 November 2008 / Accepted: 12 March 2009 / Published online: 4 April 2009

(C) 2009 The Author(s). This article is published with open access at Springerlink.com

\begin{abstract}
Background Outcome and morbidity of redo antireflux surgery are suggested to be less satisfactory than those of primary surgery. Studies reporting on redo surgery, however, are usually much smaller than those of primary surgery. The aim of this study was to summarize the currently available literature on redo antireflux surgery.

Material and Methods A structured literature search was performed in the electronic databases of MEDLINE, EMBASE, and Cochrane Central Register of Controlled Trials.

Results A total of 81 studies met the inclusion criteria. The study design was prospective in 29, retrospective in 15, and not reported in 37 studies. In these studies, 4,584 reoperations in 4,509 patients are reported. Recurrent reflux and dysphagia were the most frequent indications; intraoperative complications occurred in $21.4 \%$ and postoperative complications in $15.6 \%$, with an overall mortality rate of $0.9 \%$. The conversion rate in laparoscopic surgery was $8.7 \%$. Mean $( \pm \mathrm{SEM})$ duration of surgery was $177.4 \pm 10.3 \mathrm{~min}$ and mean hospital stay was $5.5 \pm 0.5$ days. Symptomatic outcome was successful in $81.1 \%$ and was equal in the laparoscopic and conventional approach. Objective outcome was obtained in 24 studies (29.6\%) and success was reported in $78.3 \%$, with a slightly higher success rate in case of laparoscopy than with open surgery $(85.8 \%$ vs. $78.0 \%)$.

Conclusion This systematic review on redo antireflux surgery has confirmed that morbidity and mortality after redo surgery is higher than after primary surgery and symptomatic and objective outcome are less satisfactory. Data on objective results were scarce and consistency with regard to reporting outcome is necessary.
\end{abstract}

Keywords Gastro esophageal reflux disease · Antireflux surgery $\cdot$ Nissen fundoplication $\cdot$ Dysphagia $\cdot$ Reoperation

\section{Introduction}

Antireflux surgery for refractory gastroesophageal reflux disease (GERD) has satisfactory outcome in $85-90 \%$ of

\footnotetext{
E. J. B. Furnée · H. G. Gooszen $(\bowtie)$

Department of Surgery, H.P. G04.228,

University Medical Centre Utrecht,

P.O. Box 85500, 3508 GA Utrecht, The Netherlands

e-mail: h.gooszen@umcutrecht.nl

W. A. Draaisma • I. A. M. J. Broeders

Department of Surgery, Meander Medical Centre,

Amersfoort, The Netherlands
}

patients. ${ }^{1-6}$ In the remaining $10-15 \%$, reflux symptoms persist, recur, or complications occur. Dysphagia is a frequent complication of fundoplication. ${ }^{7}$ The indications for reoperation are far from straightforward, varying from severe recurrent symptoms with a more than adequate anatomical result to recurrent abnormal anatomy without any symptoms at all. Studies on reoperations also show similar wide variations with a full range of abnormal anatomy, symptoms and objective failure documented by esophageal manometry, and $\mathrm{pH}$ monitoring.

In our recently published study on redo antireflux surgery, morbidity and mortality were higher than after primary antireflux surgery, with a symptomatic and objective success rate of $70 \%$ which is obviously inferior to the outcome of primary surgery. ${ }^{4,8}$ Several other studies have been published describing causes of failure of conventional and laparoscopic antireflux surgery. Most studies have 
included only a small group of patients, so an adequate impression on the outcome of reoperation is hard to extract from such studies.

This study aims to summarize the currently available literature on surgical reintervention after primary antireflux surgery focusing on morbidity, mortality, and outcome in order to get a more complete overview of the results of redo antireflux surgery and to give guidelines about how patients should be informed on their chances of success.

\section{Material and Methods}

\section{Search Strategy}

A literature search was performed in three electronic databases, MEDLINE using the Pubmed search engine, EMBASE, and the Cochrane Central Register of Controlled Trials. The databases were searched for all years, up to November 2008. Search terms were entered to identify the relevant studies. Separate search terms were entered for the intervention, i.e., surgical reintervention, and the disease, i.e., GERD. For the disease, dysphagia was also used because this is a frequent indication for reoperation. For both the intervention and the disease, headwords in the thesaurus of the three databases [Medical Subject Heading (MeSH) Thesaurus in Pubmed and the Cochrane library and the Emtree Thesaurus in EMBASE] and free text words in title and abstract were used as search terms. The headwords from the thesaurus and the different synonyms for free text words were coupled by the Boolean operator "OR". The combination of search terms for the intervention and disease were subsequently coupled by the Boolean operator "AND". The free text words and headwords identified in the thesauruses are listed in Table 1.

\section{Selection of Studies}

The studies identified by the search strategy were independently selected by two reviewers (E.F. and W.D.) based on title, abstract, and full text. The literature was searched for randomized controlled trials, cohort studies, and casecontrol studies on the feasibility and/or outcome of surgical reinterventions. Studies in children, on other indications for primary surgery than GERD, conservative treatment of symptoms following primary antireflux surgery, surgical reintervention within 30 days after primary surgery, and patients cohorts with less than ten patients were not included. Only articles in English were included. Addition-
Table 1 Search Terms used in this Review

\begin{tabular}{ll}
\hline Intervention & Disease \\
\hline Free text words in title and abstract of MEDLINE, EMBASE, and the Cochrane Library \\
Refundoplication(s) & Gastro esophageal reflux \\
Redo & Gastro esophageal reflux disease(s) \\
Redo surgery & Gastro esophageal reflux disorder(s) \\
Redo surgical procedure & Gastro oesophageal reflux \\
Redo Nissen (fundoplication) & Gastro oesophageal reflux disease(s) \\
Redo antireflux procedure & Gastro oesophageal reflux disorder(s) \\
Redo antireflux surgery & Gastroesophageal reflux \\
Reoperative antireflux surgery & Gastroesophageal reflux disease(s) \\
Revisional surgery & Gastroesophageal reflux disorder(s) \\
Reoperation(s) & GERD \\
Reintervention(s) & GORD \\
Surgical revision(s) & Reflux disease(s) \\
Second look surgery & Esophagitis \\
& Oesophagitis \\
Headwords in the Medical Subject Head (MeSH) Thesaurus of Pubmed and the Cochrane library \\
Reoperation & Deglutition disorders \\
Second-look surgery & Esophagitis \\
Headwords in the Emtree Thesaurus of EMBASE & \\
Reoperation & Stomach function disorder \\
Second look surgery & Dysphagia \\
& Esophagitis \\
\hline & \\
& \\
&
\end{tabular}


ally, references of all selected publications were reviewed for other relevant studies. In case of a difference in opinion between the two reviewers about in- or exclusion of a study, the opinion of a third reviewer was decisive.

\section{Analysis of Data from Selected Studies}

Data of the selected studies were independently acquired by two reviewers (E.F. and W.D.). Study design, time period, number of patients, sex ratio, and mean age were retrieved from the studies. Based on the study design, each study was qualified by a level of evidence according to the Oxford Centre for Evidence Based Medicine Levels of Evidence. ${ }^{9}$ Type and approach of primary antireflux interventions and reoperations, mean period between both interventions, causes of failure of primary surgery and perioperative information, i.e. intra- and postoperative complications, mortality, number and causes of conversions in case of laparoscopic reoperations, mean intraoperative blood loss, duration of reoperations, and hospital stay were also extracted from the included studies. Completeness of follow-up, number of patients available, mean duration of follow-up, method of obtaining outcome at follow-up, and the definition and percentage of patients with successful symptomatic and objective outcome were extracted from all studies.

\section{Data Analysis}

Data were analysed using SPSS version 15.0 for Windows (SPSS Inc., Chicago, IL, USA). Values were expressed as mean \pm SEM. Statistical analysis was not performed owing to the lack of statistically appropriate data from the included studies.

\section{Results}

\section{General Results}

One thousand six hundred twenty-five articles were eligible for further selection after removing duplicate hits, and finally, 73 articles met the inclusion criteria (Fig. 1). The references of these articles yielded eight more articles for inclusion. These articles had not been identified with the initial search strategy because of absence of abstracts in the databases or atypical description for the intervention or disease. Eventually, 81 articles were eligible for inclusion in this study. According to the Oxford Centre for Evidence Based Medicine Levels of Evidence, 27 studies had a level of evidence IIb $(33.3 \%)^{8,} 10-35$, two level of evidence IIIb $(2.5 \%)^{36,37}$, and 15 level of evidence IV $(18.5 \%)^{38-52}$. The remaining 37 studies $(45.7 \%)$ were cohort studies, but a level of evidence could not be adjudged owing to unknown study design ${ }^{53-89}$. Baseline characteristics extracted from the individual studies are shown in Table 2.

Primary Antireflux Procedures

Total fundoplication performed by laparoscopy, laparotomy, or thoracotomy was the most frequently reported primary antireflux procedure followed by partial fundoplication (Table 3). The type of primary antireflux procedure was not reported in almost one third, and 241 patients (5.3\%) underwent more than one previous operation before inclusion in the original studies.

\section{Causes of Failure of Primary Antireflux Surgery}

Causes of failure of the previous antireflux procedure were reported on 3,175 reoperations in total. Intrathoracic wrap migration, total or partial disruption of the wrap, and telescoping were the most common anatomical abnormalities encountered (Table 4). Esophageal motility disorder or erroneous diagnosis, i.e., another primary disease than GERD, were the causes of failure of the previous operation in 62 patients $(2.0 \%)$. In 194 reoperations $(6.1 \%)$, no cause of failure could be identified.

From six studies, it was shown that wrap disruption and telescoping were more frequent after conventional primary surgery, whereas disruption of hiatal repair and a tight wrap were more frequent after laparoscopic primary repair (Table 5). ${ }^{18,49,61,67,84,85}$ Intrathoracic wrap migration was reported by Serafina et al. ${ }^{85}$ to be more frequent after conventional primary procedures $(13 / 17,76.5 \%$ vs. $5 / 11$, $45.5 \%$ ), whereas Heniford et al. ${ }^{67}$ showed that this was more frequent after laparoscopic primary repair (16/22, $72.7 \%$ vs. $13 / 33,39.4 \%$ ). In the study by Salminen et al., ${ }^{84}$ intrathoracic wrap migration was equal after conventional and laparoscopic primary surgery.

In five other studies, ${ }^{8,11,12,31,72}$ it was shown that intrathoracic wrap migration and wrap disruption were more frequent in the case of recurrent reflux, whereas in the case of dysphagia, no cause of failure could be demonstrated more frequently (Table 5).

\section{Indications for Reoperations}

Recurrent reflux and dysphagia were the most frequent indications for reoperations (Table 3). In 1,435 reoperations $(31.3 \%)$, the indication for reoperation was not reported. Preoperative symptoms were assessed by questionnaire in 26 studies (32.1\%). ${ }^{10,14,17,18,23-25,28,30,33,36,45,53,54,56,61-}$ $66,71,74,76,87,88$ In most studies (93.8\%), preoperative workup consisted of esophagogastroduodenoscopy, barium 
Figure 1 Results of Search Strategy and Selection of Studies.

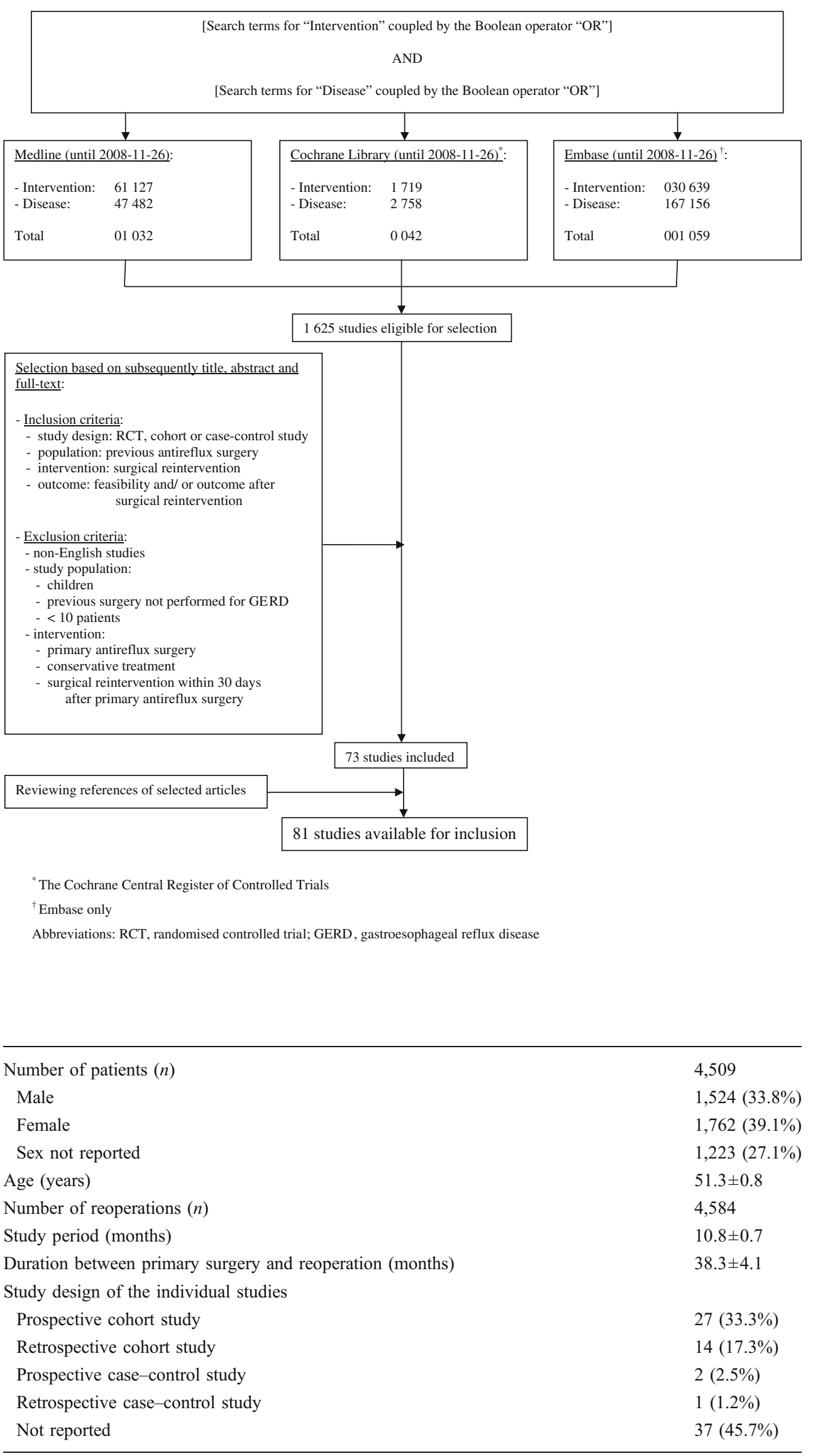

Table 2 Baseline Characteristics Extracted from the Included Studies

Values are given as mean \pm SEM unless otherwise stated 
Table 3 Type and Indication of Primary Antireflux Procedures and Reoperations

\begin{tabular}{llc}
\hline & Primary procedures $(n=4,750)$ & Reoperations $(n=4,584)$ \\
\hline Indication of operations & & \\
Recurrent reflux & - & $1,912(41.7 \%)$ \\
Dysphagia & - & $760(16.6 \%)$ \\
Recurrent reflux and dysphagia & - & $184(4.0 \%)$ \\
Anatomical abnormality & - & $114(2.5 \%)$ \\
Gasbloat syndrome & - & $31(0.7 \%)$ \\
Miscellaneous & - & $148(3.2 \%)$ \\
Not reported & - & $1,435(31.3 \%)$ \\
Type of operations & & \\
Total fundoplication & $2,162(45.5 \%)$ & $2,397(52.3 \%)$ \\
Partial fundoplication & $471(9.9 \%)$ & $999(21.8 \%)$ \\
Resection surgery & - & $327(7.1 \%)$ \\
Miscellaneous procedures & $657(13.8 \%)$ & $737(16.1 \%)$ \\
Not reported & $1,460(30.7 \%)$ & $124(2.7 \%)$ \\
\hline
\end{tabular}

swallow, and/or esophageal $\mathrm{pH}$ monitoring. ${ }^{10-28,30-41,43-}$ $46,48-76,78,79,81-89$

\section{Type and Route of Reoperations}

Total or partial fundoplication was the most frequently performed reoperation (Table 3), whereas the type of reoperation was not reported in 124 patients $(2.7 \%)$. The laparoscopic approach was used in 1,666 reoperations (36.3\%); 1,589 reoperations $(34.7 \%)$ were performed by the conventional (open) abdominal route and 1,041 (22.7\%)

Table 4 Causes of Failure of Previous Antireflux Procedure

\begin{tabular}{lc}
\hline & $n=3,175$ \\
\hline Anatomical abnormalities & \\
Intrathoracic wrap migration & $885(27.9 \%)$ \\
Wrap disruption & $722(22.7 \%)$ \\
Telescoping & $448(14.1 \%)$ \\
Para-esophageal hiatal herniation & $195(6.1 \%)$ \\
Hiatal disruption & $167(5.3 \%)$ \\
Tight wrap & $168(5.3 \%)$ \\
Stricture & $60(1.9 \%)$ \\
Wrong primary diagnosis & \\
Achalasia & $37(1.2 \%)$ \\
Esophageal spasms & $7(0.2 \%)$ \\
Sclerodermia & $4(0.1 \%)$ \\
Esophageal carcinoma & $1(0.03 \%)$ \\
Disturbed esophageal motility & $13(0.4 \%)$ \\
No cause for failure identified & $194(6.1 \%)$ \\
Miscellaneous & $347(10.9 \%)$ \\
Not reported & $120(3.8 \%)$ \\
\hline
\end{tabular}

Percentages exceed $100 \%$ since more than one cause of failure was found during several reoperations by thoracotomy. The approach of reoperation was not reported in the remaining 288 reoperations (6.3\%). More than one reintervention was performed in 75 patients $(1.7 \%)$.

The esophagus was totally or partially resected during 125 reoperations $(2.7 \%)$. The reasons to perform esophageal resection were severe esophagitis with or without Barrett metaplasia, ${ }^{15,25,59}$ peptic stricture of the esophagus, ${ }^{10,33,51,57,72,81}$ severely disturbed esophageal motility, ${ }^{26,44,57,81}$ or short esophagus. $^{70,82}$ In 202 reoperations (4.4\%), gastric resection was performed. Indications for this were alkaline reflux, ${ }^{10}$ dense adhesions on attempted refundoplication, ${ }^{33,59,86}$ or severe gastric paresis..$^{25,81}$

\section{Intra- and Postoperative Results}

The different intra- and postoperative parameters were only reported in a subset of the original studies. Intraoperative complications were reported in 454 of 2,123 reoperations (21.4\%) and were more frequent during laparoscopic than during open abdominal reoperations $(150 / 770,19.5 \%$ vs. $5 / 92,5.4 \%$ ). Laceration or perforation of the esophagus and/or stomach was the most common (Table 6). Postoperative complications were present after 546 of 3,491 reoperations (15.6\%). Infectious, pulmonary, and cardiac complications were the most common postoperative complications (Table 6). Open abdominal reoperations were accompanied with more complications than laparoscopic reoperations $(55 / 317,17.4 \%$ vs. $98 / 642,15.3 \%)$. Thirtyseven of 4,329 patients $(0.9 \%)$ died intra- or postoperatively (Table 6). No mortality occurred in studies only reporting on laparoscopic reoperations, while the mortality rate was $1.3 \%$ in studies in which all reoperations were performed by a conventional abdominal approach.

Mean duration of reoperation was $177.4 \pm 10.3 \mathrm{~min}$, mean intraoperative blood loss $205.5 \pm 35.6 \mathrm{ml}$, and mean 
Table 5 Anatomical Abnormalities Depending on the Approach of Primary Surgery and the Indication of Reoperation

\begin{tabular}{lcc}
\hline Anatomical abnormalities depending on the approach of primary surgery & \\
& Conventional (abdominal) approach $(n=120)$ & $24(18.2 \%)$ \\
Wrap disruption & $48(40.0 \%)$ & $10(7.6 \%)$ \\
Telescoping & $32(26.6 \%)$ & $42(31.8 \%)$ \\
Hiatal disruption & $23(19.2 \%)$ & $24(18.2 \%)$ \\
Tight wrap & $2(1.7 \%)$ & $42(31.8 \%)$ \\
Miscellaneous & $36(30.0 \%)$ & Dysphagia $(n=118)$ \\
Anatomical abnormalities depending on the indication of reoperation & $18(15.3 \%)$ \\
& Recurrent reflux $(n=234)$ & $12(10.2 \%)$ \\
Intrathoracic wrap migration & $104(44.4 \%)$ & $51(43.2 \%)$ \\
Wrap disruption & $109(46.6 \%)$ & $54(45.8 \%)$ \\
No cause of failure & $34(14.5 \%)$ & $64(27.4 \%)$ \\
Miscellaneous & & \\
\hline
\end{tabular}

Percentages exceed $100 \%$ since more than one cause of failure was found during several reoperations

hospital stay $5.5 \pm 0.5$ days. Comparing results of laparoscopic reoperations with laparotomy regarding the preceding parameters was not possible due to the small number of well-documented studies in the laparotomy group.

Reoperation was performed laparoscopically in $36.3 \%$ of all cases with a conversion rate of $8.7 \%$. Causes of conversion were dense adhesions $(n=57,39.3 \%)$, severe

Table 6 Intra- and Postoperative Results of Reoperations

\begin{tabular}{ll}
\hline Intraoperative complications & $N=2,123^{\mathrm{a}}$ \\
Injury of esophagus and stomach & $278(13.1 \%)$ \\
Pneumothorax & $73(3.4 \%)$ \\
Hemorrhage & $41(1.9 \%)$ \\
Splenectomy & $7(0.3 \%)$ \\
Other & $49(2.3 \%)$ \\
Not reported & $6(0.3 \%)$ \\
Postoperative complications & $N=3491^{\mathrm{a}}$ \\
Pulmonary complication & $125(3.6 \%)$ \\
Wound infection & $64(1.8 \%)$ \\
Leakage from alimentary tract & $52(1.5 \%)$ \\
Urinary tract infection & $12(0.3 \%)$ \\
Other infectious complications & $48(1.4 \%)$ \\
Cardiac complications & $31(0.9 \%)$ \\
Hemorrhage & $22(0.6 \%)$ \\
Other & $136(3.9 \%)$ \\
Not reported & $56(1.6 \%)$ \\
Causes of mortality & $N=4,329^{\mathrm{a}}$ \\
Infectious & $11(0.3 \%)$ \\
Pulmonary & $7(0.2 \%)$ \\
Cardiac & $4(0.1 \%)$ \\
Miscellaneous & $10(0.2 \%)$ \\
Not reported & $5(0.1 \%)$ \\
\hline
\end{tabular}

${ }^{a}$ Total number of reoperations in which the intra- and postoperative complications and mortality rate were reported intraoperative bleeding $(n=11,7.6 \%)$, poor visualization $(n=3,2.1 \%)$, and other $(n=15,10.3 \%)$. In the remaining 59 cases $(40.7 \%)$, the reason for conversion was not reported.

\section{Symptomatic Outcome after Reoperations}

Symptomatic outcome after reoperation was determined in 79 studies $(97.5 \%)^{8,10-18,20-28,30-89}$ and reported as successful in $81 \%$ of patients, although with different definitions of success (Table 7). Data were obtained by questionnaires in 29 studies $(36.7 \%), 8,10,11,16-18,20,22-$ $24,27,28,30,34-37,42,45,46,48,49,54,55,61,69,71,80,84$ by interview in $21(26.6 \%),{ }^{13,25,31,38,41,47,52,53,57,60,62,65-68,73,74,78,82,83,85}$ and this was not reported in the remaining 29 studies $(36.7 \%)$. $^{12,14,15,21,26,32,33,39,40,43,44,50,51,56,58,59,63,64,70,72,75-}$ $77,79,81,86-89$ The mean success rate in studies only reporting on laparoscopic reoperations (17 studies $)^{11-13,23-}$ $25,28,31,35,39,41,48,50,53,61,70,85$ was $84.2 \pm 2.5 \%$ and $84.6 \pm$ $3.4 \%$ in studies in which all reoperations were performed by a conventional abdominal approach (ten studies). ${ }^{10,22,33,44,58,68,69,75,76,86}$ In patients in whom the reoperation was performed for symptoms only, $82.0 \pm 10.7 \%$ had successful symptomatic outcome, ${ }^{47,79}$ and the success rate was $81.0 \pm 12.1 \%$ in patients with recurrent reflux documented by $\mathrm{pH}$ monitoring. ${ }^{10,12,56,89}$ Comparing the outcome of total and partial refundoplication, Awad et al. ${ }^{53}$ reported symptomatic success in $68 \%$ and $60 \%$ of patients, respectively. In two other studies, ${ }^{11,45}$, however, no relationship between the type of fundoplication and the symptomatic outcome was found.

\section{Objective Outcome after Reoperations}

Objective outcome was reported in 696 patients $(15.4 \%)$ in 24 studies $(29.6 \%)$, without a definition of success ${ }^{17,18,20}$ or 
Table 7 Symptomatic and Objective Outcome after Reoperation

\begin{tabular}{lcc}
\hline Definition of successful symptomatic outcome in the individual studies & $\begin{array}{l}\text { Symptomatic outcome } \\
n=79\end{array}$ & Objective outcome \\
\hline Degree of symptoms at follow-up & $25(31.6 \%)$ & - \\
Patient satisfaction & $22(27.8 \%)$ & - \\
$\quad$ Satisfaction defined & $6(27.3 \%)$ & - \\
Satisfaction not defined & $16(72.7 \%)$ & - \\
Visick grading system & $7(8.9 \%)$ & - \\
Visick grading system combined with patient satisfaction & $1(1.3 \%)$ & - \\
Scores calculated from specific quality of life questionnaires & $5(6.3 \%)$ & - \\
Miscellaneous & $5(6.3 \%)$ & - \\
Not reported & $14(17.7 \%)$ & $581(12.9 \%)$ \\
Patients available at follow-up & $3338(74.0 \%)$ & $21.8 \pm 4.7$ \\
Duration of follow-up (months) & $34.2 \pm 2.7$ & $455(78.3 \%)$ \\
Patients with successful outcome & $2706(81.1 \%)$ & \\
\hline
\end{tabular}

Values are given as mean \pm SEM unless otherwise stated

the number of successful cases, ${ }^{14,17,18,20,28,49,87}$ however, in seven studies. In the remaining 17 studies, successful objective outcome was defined as normal acid exposure during $\mathrm{pH}$ monitoring in $11,8,15,19,23,25,36,38,51,57,58,88$ absence of esophagitis in four, ${ }^{10,54,59,76}$ combination of these both in one, ${ }^{75}$ and the absence of reflux during radiologic imaging in another one. ${ }^{65}$ In these 17 studies, $78 \%$ had a successful objective outcome (Table 7). The mean success rate of laparoscopic reoperation (four studies ${ }^{19,23,25,88}$ ) seemed higher than in the case of a conventional abdominal approach (four other studies ${ }^{10,58,75,76}$ ), $85.8 \pm 5.6 \%$ and $78.0 \pm 10.1 \%$, respectively.

\section{Discussion}

The often reported observations that morbidity and mortality are higher after redo antireflux surgery and symptomatic outcome is inferior to primary antireflux surgery have been confirmed in this systematic review on all studies currently available. Very few had a prospective study design, and in almost half of all, the type of analysis was not even reported. Moreover, most studies only present symptomatic outcome, and data on anatomy and function of the esophagogastric junction are scarce.

Morbidity was most frequently caused by direct injury of the esophagus and stomach during reoperation in the current review, and this was confirmed in our own data on redo surgery, ${ }^{8}$ mainly as a result of increased complexity due to adhesions after the primary operation. Most primary interventions in the studies reviewed were performed by the conventional approach. Nowadays, with laparoscopy as the golden standard, less adhesions may be encountered if redo surgery is required. This might improve the outlook for these patients with a lower chance of iatrogenic organ damage, but this has to be proven in future studies. Although postoperative morbidity and mortality appeared to be lower after laparoscopic reoperations compared to the open abdominal approach, intraoperative complications occurred more frequently during laparoscopic surgery. These data, however, are not based on comparison between both approaches within individual studies, and therefore, this should, in our opinion, be interpreted with caution.

The cause of failure was recognized in $93.8 \%$ and mainly consisted of anatomical abnormalities or an erroneous indication for primary surgery. Disruption of hiatal repair and a too tight wrap were more frequently observed after the laparoscopic than after the open approach. This again underlines the difficulty of doing an adequate hiatal repair and creating a "floppy" wrap by laparoscopy. Achalasia was the most frequently reported incorrect diagnosis as the cause of failure, and this supports the inclusion of esophageal manometry and 24-h $\mathrm{pH}$ monitoring in the preoperative workup. It has also been suggested that a too tight fundoplication can cause an achalasia-like clinical picture. ${ }^{90}$ Esophageal manometry shows, in those circumstances, a non-relaxing lower esophageal sphincter, but not an aperistaltic esophagus. ${ }^{91}$

Preoperative workup before reoperation is, apparently, not standardized but tailored to the cause of failure and the indication for reoperation. In the case of dysphagia, this consists of barium swallow to evaluate the esophageal and gastric anatomy and esophageal manometry to detect whether or not a motility disorder may be an (additional) cause of failure. In patients with reflux symptoms, extensive reevaluation is essential. Symptoms have been shown, however, to be bad predictors of pathological reflux after primary antireflux surgery ${ }^{92}$ and unrelated to anatom- 
ical wrap position. ${ }^{93}$ Therefore, objective preoperative workup is equal to patients evaluated for primary antireflux surgery and consists of esophagogastroduodenoscopy, esophageal manometry, and 24-h pH monitoring, completed with barium swallow to evaluate the anatomy in addition to endoscopy.

Symptomatic outcome was described in most studies in this review with a success rate ranging from $56 \%$ to $100 \%$. The definitions for success showed considerable variation and focus either on a more general or overall system or on specific symptoms with or without mentioning data on quality of life and the effect of surgery on quality of life aspects, compromising comparison between the individual studies. Patient satisfaction was a frequently used method for scoring symptomatic outcome. Patient's satisfaction is important and clinically highly relevant, but it does not directly refer to the specific symptoms of the disease, and consequently, this type of scoring does not provide insight in which aspects of the disease have improved and whether or not reflux symptoms have been exchanged by, for example, dysphagia. The Visick grading system, indicating that the disease was cured or improved with Visick grades I and II or unchanged or worsened in grades III and IV considered a symptomatic failure, ${ }^{94}$ correlated well with postoperative daily reflux related symptoms and daily complaints of dysphagia in our patient group on redo antireflux surgery. ${ }^{8}$

Objective outcome was only reported in less than one third of the included studies in this review, with a mean success rate of $78 \%$, which is slightly worse than after primary surgery. In our unit, all patients are encouraged to undergo stationary esophageal manometry and ambulatory 24-hr esophageal $\mathrm{pH}$ monitoring before and after primary as well as redo antireflux surgery primarily for quality control, but also to be able to correlate the functional results with symptoms and to understand possible future symptoms. Although previous studies have shown that for a good symptomatic outcome after primary surgery optimal anatomical and functional results are not a prerequisite, ${ }^{92,93}$ more studies reporting the anatomical and functional status of the esophagus and stomach after redo surgery are required to outline a more complete overall picture of the outcome of redo antireflux surgery.

\section{Conclusion}

Redo antireflux surgery has a higher morbidity and mortality rate than primary antireflux surgery and symptomatic outcome is less satisfactory. Consistency with regard to reporting on symptomatic and objective outcome is necessary. Data on objective results after redo antireflux surgery are scarce and a plea can be made to subject all primary cases to full-scale evaluation, before and after antireflux surgery. Data to support this suggestion with evidence, like adequate cost-effectiveness studies, are lacking. The relative disappointing results of redo antireflux surgery with regard to morbidity, mortality, and symptomatic outcome support the opinion that redo surgery is tertiary referral center surgery and these centers should continue their efforts to collect prospective subjective and objective data.

\section{No financial support.}

Open Access This article is distributed under the terms of the Creative Commons Attribution Noncommercial License which permits any noncommercial use, distribution, and reproduction in any medium, provided the original author(s) and source are credited.

\section{References}

1. Anvari M, Allen C. Five-year comprehensive outcomes evaluation in 181 patients after laparoscopic Nissen fundoplication. J Am Coll Surg 2003;196:51-57. doi:10.1016/S1072-7515(02)01604-6.

2. Booth MI, Jones L, Stratford J, Dehn TC. Results of laparoscopic Nissen fundoplication at 2-8 years after surgery. Br J Surg 2002;89:476-481. doi:10.1046/j.0007-1323.2002.02074.x.

3. De Meester TR, Bonavina L, Albertucci M. Nissen fundoplication for gastroesophageal reflux disease. Evaluation of primary repair in 100 consecutive patients. Ann Surg 1986;204:9-20. doi:10.1097/00000658-198607000-00002.

4. Draaisma WA, Rijnhart-de Jong HG, Broeders IA, Smout AJ, Furnee EJ, Gooszen HG. Five-year subjective and objective results of laparoscopic and conventional Nissen fundoplication: A randomized trial. Ann Surg 2006;244:34-41. doi:10.1097/01. sla.0000217667.55939.64.

5. Grande L, Toledo-Pimentel V, Manterola C, Lacima G, Ros E, Garcia-Valdecasas JC et al. Value of Nissen fundoplication in patients with gastro-oesophageal reflux judged by long-term symptom control. Br J Surg 1994;81:548-550. doi:10.1002/ bjs. 1800810421 .

6. Rossetti M, Hell K. Fundoplication for the treatment of gastroesophageal reflux in hiatal hernia. World J Surg 1977;1:439-443. doi:10.1007/BF01565907.

7. Gott JP, Polk HC Jr. Repeat operation for failure of antireflux procedures. Surg Clin North Am 1991;71:13-32.

8. Furnee EJ, Draaisma WA, Broeders IA, Smout AJ, Gooszen HG. Surgical reintervention after antireflux surgery for gastroesophageal reflux disease: A prospective cohort study in 130 patients. Arch Surg 2008;143:267-274. doi:10.1001/archsurg.2007.50.

9. Centre for Evidence-Based Medicine. 2008. Available from http:// www.cebm.net/?o = 1023 (cited 2008 Oct. 22)

10. Braghetto I, Csendes A, Burdiles P, Botero F, Korn O. Results of surgical treatment for recurrent postoperative gastroesophageal reflux. Dis Esophagus 2002;15:315-322. doi:10.1046/j.14422050.2002.00274.x.

11. Byrne JP, Smithers BM, Nathanson LK, Martin I, Ong HS, Gotley DC. Symptomatic and functional outcome after laparoscopic reoperation for failed antireflux surgery. Br J Surg 2005;92:9961001. doi:10.1002/bjs.4914. 
12. Coelho JC, Goncalves CG, Claus CM, Andrigueto PC, Ribeiro $\mathrm{MN}$. Late laparoscopic reoperation of failed antireflux procedures. Surg Laparosc Endosc Percutan Tech 2004;14:113-117. doi:10.1097/01.sle.0000129393.57748.ac.

13. Curet MJ, Josloff RK, Schoeb O, Zucker KA. Laparoscopic reoperation for failed antireflux procedures. Arch Surg 1999;134:559-563. doi:10.1001/archsurg.134.5.559.

14. Dutta S, Bamehriz F, Boghossian T, Pottruff CG, Anvari M. Outcome of laparoscopic redo fundoplication. Surg Endosc 2004;18:440-443. doi:10.1007/s00464-003-8822-5.

15. Franzen T, Johansson KE. Symptoms and reflux competence in relation to anatomical findings at reoperation after laparoscopic total fundoplication. Eur J Surg 2002;168:701-706.

16. Gee DW, Andreoli MT, Rattner DW. Measuring the effectiveness of laparoscopic antireflux surgery: Long-term results. Arch Surg 2008;143:482-487. doi:10.1001/archsurg.143.5.482.

17. Granderath FA, Kamolz T, Schweiger UM, Pasiut M, Haas CF, Wykypiel $\mathrm{H}$ et al. Is laparoscopic refundoplication feasible in patients with failed primary open antireflux surgery? Surg Endosc 2002;16:381-385. doi:10.1007/s00464-001-9102-x.

18. Granderath FA, Kamolz T, Schweiger UM, Pointner R. Failed antireflux surgery: Quality of life and surgical outcome after laparoscopic refundoplication. Int J Colorectal Dis 2003;18:248253. doi:10.1007/s00384-002-0405-8.

19. Granderath FA, Kamolz T, Schweiger UM, Pointner R. Laparoscopic refundoplication with prosthetic hiatal closure for recurrent hiatal hernia after primary failed antireflux surgery. Arch Surg 2003;138:902-907. doi:10.1001/archsurg.138.8.902.

20. Granderath FA, Granderath UM, Pointner R. Laparoscopic revisional fundoplication with circular hiatal mesh prosthesis: The long-term results. World J Surg 2008;32:999-1007. doi:10.1007/s00268-008-9558-0.

21. Hunter JG, Smith CD, Branum GD, Waring JP, Trus TL, Cornwell $\mathrm{M}$ et al. Laparoscopic fundoplication failures: Patterns of failure and response to fundoplication revision. Ann Surg 1999;230:595604. doi:10.1097/00000658-199910000-00015.

22. Johnsson E, Lundell L. Repeat antireflux surgery: Effectiveness of a Toupet partial posterior fundoplication. Eur J Surg 2002;168:441-445. doi:10.1080/110241502321116415.

23. Kamolz T, Granderath FA, Bammer T, Pasiut M, Pointner R. Failed antireflux surgery: Surgical outcome of laparoscopic refundoplication in the elderly. Hepatogastroenterology 2002;49:865-868.

24. Kamolz T, Granderath PA, Bammer T, Pasiut M, Wykypiel H Jr, Herrmann R et al. Mid- and long-term quality of life assessments after laparoscopic fundoplication and refundoplication: A single unit review of more than 500 antireflux procedures. Dig Liver Dis 2002;34:470-476. doi:10.1016/S1590-8658(02)80104-9.

25. Khajanchee YS, O'Rourke R, Cassera MA, Gatta P, Hansen PD, Swanstrom LL. Laparoscopic reintervention for failed antireflux surgery: Subjective and objective outcomes in 176 consecutive patients. Arch Surg 2007;142:785-901. doi:10.1001/archsurg.142.8.785.

26. Khan OA, Kanellopoulos G, Field ML, Knowles KR, Beggs FD, Morgan WE et al. Redo antireflux surgery-The importance of a tailored approach. Eur J Cardiothorac Surg 2004;26:875-880. doi:10.1016/j.ejcts.2004.07.037.

27. Legare JF, Henteleff HJ, Casson AG. Results of Collis gastroplasty and selective fundoplication, using a left thoracoabdominal approach, for failed antireflux surgery. Eur J Cardiothorac Surg 2002;21:534-540. doi:10.1016/S1010-7940(02)00003-9.

28. Oelschlager BK, Lal DR, Jensen E, Cahill M, Quiroga E, Pellegrini CA. Medium- and long-term outcome of laparoscopic redo fundoplication. Surg Endosc 2006;20:1817-1823. doi:10.1007/s00464-005-0262-y.

29. Pohl D, Eubanks TR, Omelanczuk PE, Pellegrini CA. Management and outcome of complications after laparoscopic antireflux operations. Arch Surg 2001;136:399-404. doi:10.1001/archsurg. 136.4.399.

30. Rosemurgy AS, Arnaoutakis DJ, Thometz DP, Binitie O, Giarelli $\mathrm{NB}$, Bloomston $\mathrm{M}$ et al. Reoperative fundoplications are effective treatment for dysphagia and recurrent gastroesophageal reflux. Am Surg 2004;70:1061-1067.

31. Safranek PM, Gifford CJ, Booth MI, Dehn TC. Results of laparoscopic reoperation for failed antireflux surgery: Does the indication for redo surgery affect the outcome? Dis Esophagus 2007;20:341-345. doi:10.1111/j.1442-2050.2007.00719.x.

32. Smith CD, McClusky DA, Rajad MA, Lederman AB, Hunter JG. When fundoplication fails: Redo? Ann Surg 2005;241:861-869. doi:10.1097/01.sla.0000165198.29398.4b.

33. Stein HJ, Feussner H, Siewert JR. Failure of antireflux surgery: Causes and management strategies. Am J Surg 1996;171:36-39. doi:10.1016/S0002-9610(99)80070-1.

34. Watson AJ, Krukowski ZH. Revisional surgery after failed laparoscopic anterior fundoplication. Surg Endosc 2002;16:392394. doi:10.1007/s00464-001-9060-3.

35. Watson DI, Jamieson GG, Game PA, Williams RS, Devitt PG. Laparoscopic reoperation following failed antireflux surgery. Br J Surg 1999;86:98-101. doi:10.1046/j.1365-2168.1999.00976.x.

36. Bais JE, Wijnhoven BP, Masclee AA, Smout AJ, Gooszen HG. Analysis and surgical treatment of persistent dysphagia after Nissen fundoplication. Br J Surg 2001;88:569-576. doi:10.1046/ j.1365-2168.2001.01724.x.

37. Cowgill SM, Arnaoutakis D, Villadolid D, Rosemurgy AS. "Redo" fundoplications: Satisfactory symptomatic outcomes with higher cost of care. J Surg Res 2007;143:183-188. doi:10.1016/j. jss.2007.03.078.

38. Avaro JP, D'Journo XB, Trousse D, Ouattara MA, Doddoli C, Giudicelli $\mathrm{R}$ et al. Long-term results of redo gastro-esophageal reflux disease surgery. Eur J Cardiothorac Surg 2008;33:10911095. doi:10.1016/j.ejcts.2008.01.066.

39. Bataille D, Simoens C, Mendes da CP. Laparoscopic revision for failed anti-reflux surgery. Preliminary results. Hepatogastroenterology 2006;53:86-88.

40. Deschamps C, Trastek VF, Allen MS, Pairolero PC, Johnson JO, Larson DR. Long-term results after reoperation for failed antireflux procedures. J Thorac Cardiovasc Surg 1997;113:545-550. doi:10.1016/S0022-5223(97)70369-6.

41. Floch NR, Hinder RA, Klingler PJ, Branton SA, Seelig MH, Bammer $\mathrm{T}$ et al. Is laparoscopic reoperation for failed antireflux surgery feasible? Arch Surg 1999;134:733-737. doi:10.1001/ archsurg.134.7.733.

42. Fumagalli U, Bona S, Battafarano F, Zago M, Barbera R, Rosati R. Persistent dysphagia after laparoscopic fundoplication for gastro-esophageal reflux disease. Dis Esophagus 2008;21:257261. doi:10.1111/j.1442-2050.2007.00773.x.

43. Hatch KF, Daily MF, Christensen BJ, Glasgow RE. Failed fundoplications. Am J Surg 2004;188:786-791. doi:10.1016/j. amjsurg.2004.08.062.

44. Hatton PD, Selinkoff PM, Harford FJ Jr. Surgical management of the failed Nissen fundoplication. Am J Surg 1984;148:760-763. doi:10.1016/0002-9610(84)90432-X.

45. Khaitan L, Bhatt P, Richards W, Houston H, Sharp K, Holzman M. Comparison of patient satisfaction after redo and primary fundoplications. Surg Endosc 2003;17:1042-1045. doi:10.1007/ s00464-002-8846-2.

46. Luketich JD, Fernando HC, Christie NA, Buenaventura PO, Ikramuddin S, Schauer PR. Outcomes after minimally invasive reoperation for gastroesophageal reflux disease. Ann Thorac Surg 2002;74:328-331. doi:10.1016/S0003-4975(02)03713-X.

47. Maher JW, Hocking MP, Woodward ER. Reoperations for esophagitis following failed antireflux procedures. Ann Surg 1985;201:723-727. doi:10.1097/00000658-198506000-00008. 
48. Papasavas PK, Yeaney WW, Landreneau RJ, Hayetian FD, Gagne DJ, Caushaj PF et al. Reoperative laparoscopic fundoplication for the treatment of failed fundoplication. J Thorac Cardiovasc Surg 2004;128:509-516. doi:10.1016/j.jtcvs.2004.04.037.

49. Pointner R, Bammer T, Then P, Kamolz T. Laparoscopic refundoplications after failed antireflux surgery. Am J Surg 1999;178:541-544. doi:10.1016/S0002-9610(99)00215-9.

50. Richardson WS. Laparoscopic reoperative surgery after laparoscopic fundoplication: An initial experience. Curr Surg 2004;61:583-586. doi:10.1016/j.cursur.2004.04.003.

51. Stirling MC, Orringer MB. Surgical treatment after the failed antireflux operation. J Thorac Cardiovasc Surg 1986;92:667672.

52. Williams VA, Watson TJ, Gellersen O, Feuerlein S, Molena D, Sillin LF et al. Gastrectomy as a remedial operation for failed fundoplication. J Gastrointest Surg 2007;11:29-35. doi:10.1007/ s11605-006-0048-0.

53. Awad ZT, Anderson PI, Sato K, Roth TA, Gerhardt J, Filipi CJ. Laparoscopic reoperative antireflux surgery. Surg Endosc 2001;15:1401-1407.

54. Bais JE, Horbach TL, Masclee AA, Smout AJ, Terpstra JL, Gooszen HG. Surgical treatment for recurrent gastro-oesophageal reflux disease after failed antireflux surgery. $\mathrm{Br} \mathrm{J}$ Surg 2000;87:243-249. doi:10.1046/j.1365-2168.2000.01299.x.

55. Bonavina L, Chella B, Segalin A, Incarbone R, Peracchia A. Surgical therapy in patients with failed antireflux repairs. Hepatogastroenterology 1998;45:1344-1347.

56. Braghetto I, Csendes A, Nava O, Henriquez A, Quesada S. Clinical and laboratory characteristics and surgical alternatives in patients with postoperative recurrent reflux esophagitis. Dig Surg 1993;10:59-64. doi:10.1159/000172143.

57. Collard JM, Verstraete L, Otte JB, Fiasse R, Goncette L, Kestens PJ. Clinical, radiological and functional results of remedial antireflux operations. Int Surg 1993;78:298-306.

58. Collard JM, Romagnoli R, Kestens PJ. Reoperation for unsatisfactory outcome after laparoscopic antireflux surgery. Dis Esophagus 1996;9:56-62.

59. DePaula AL, Hashiba K, Bafutto M, Machado CA. Laparoscopic reoperations after failed and complicated antireflux operations. Surg Endosc 1995;9:681-686. doi:10.1007/BF00187939.

60. Ellis FH Jr, Gibb SP, Heatley GJ. Reoperation after failed antireflex surgery. Review of 101 cases. Eur J Cardiothorac Surg 1996;10:225-231. doi:10.1016/S1010-7940(96)80143-6.

61. Granderath FA, Kamolz T, Schweiger UM, Pointner R. Long-term follow-up after laparoscopic refundoplication for failed antireflux surgery: Quality of life, symptomatic outcome, and patient satisfaction. J Gastrointest Surg 2002;6:812-818. doi:10.1016/ S1091-255X(02)00089-6.

62. Haider M, Iqbal A, Salinas V, Karu A, Mittal SK, Filipi CJ. Surgical repair of recurrent hiatal hernia. Hernia 2006;10:13-19. doi:10.1007/s10029-005-0034-6.

63. Henderson RD. Nissen hiatal hernia repair: Problems of recurrence and continued symptoms. Ann Thorac Surg 1979;28:587593.

64. Henderson RD, Marryatt G. Recurrent hiatal hernia: management by thoracoabdominal total fundoplication gastroplasty. Can J Surg 1981;24:151-157.

65. Henderson RD. Surgical management of the failed gastroplasty. J Thorac Cardiovasc Surg 1986;91:46-52.

66. Henderson RD, Marryatt G, Henderson RF. Review of the surgical management of recurrent hiatal hernia: 5-year followup. Can J Surg 1988;31:341-345.

67. Heniford BT, Matthews BD, Kercher KW, Pollinger H, Sing RF. Surgical experience in fifty-five consecutive reoperative fundoplications. Am Surg 2002;68:949-954.
68. Hill LD. Management of recurrent hiatal hernia. Arch Surg 1971;102:296-302.

69. Hill LD, Ilves R, Stevenson JK, Pearson JM. Reoperation for disruption and recurrence after Nissen fundoplication. Arch Surg 1979;114:542-548.

70. Horgan S, Pohl D, Bogetti D, Eubanks T, Pellegrini C. Failed antireflux surgery: What have we learned from reoperations? Arch Surg 1999;134:809-815. doi:10.1001/archsurg.134.8.809.

71. Iqbal A, Awad Z, Simkins J, Shah R, Haider M, Salinas V et al. Repair of 104 failed anti-reflux operations. Ann Surg 2006;244:42-51. doi:10.1097/01.sla.0000217627.59289.eb.

72. Leonardi HK, Crozier RE, Ellis FH Jr. Reoperation for complications of the Nissen fundoplication. J Thorac Cardiovasc Surg 1981;81:50-56.

73. Lim JK, Moisidis E, Munro WS, Falk GL. Re-operation for failed anti-reflux surgery. Aust N Z J Surg 1996;66:731-733. doi:10.1111/j.1445-2197.1996.tb00731.x.

74. Little AG, Ferguson MK, Skinner DB. Reoperation for failed antireflux operations. J Thorac Cardiovasc Surg. 1986;91:511-517.

75. Luostarinen ME, Isolauri JO, Koskinen MO, Laitinen JO, Matikainen MJ, Lindholm TS. Refundoplication for recurrent gastroesophageal reflux. World J Surg 1993;17:587-593. doi:10.1007/BF01659115.

76. Martin CJ, Crookes PF. Reoperation for failed antireflux surgery. Aust N Z J Surg 1990;60:773-778. doi:10.1111/j.14452197.1990.tb07472.x.

77. Neuhauser B, Hinder RA. Laparoscopic reoperation after failed antireflux surgery. Semin Laparosc Surg 2001;8:281-286. doi:10.1053/slas.2001.30172.

78. Ohnmacht GA, Deschamps C, Cassivi SD, Nichols FC 3rd, Allen MS, Schleck CD et al. Failed antireflux surgery: results after reoperation. Ann Thorac Surg 2006;81:2050-2053. doi:10.1016/j. athoracsur.2006.01.019.

79. Orringer MB, Skinner DB, Belsey RH. Long-term results of the Mark IV operation for hiatal hernia and analyses of recurrences and their treatment. J Thorac Cardiovasc Surg 1972;63:25-33.

80. Pearson FG, Cooper JD, Patterson GA, Ramirez J, Todd TR. Gastroplasty and fundoplication for complex reflux problems. Long-term results. Ann Surg 1987;206:473-481. doi:10.1097/ 00000658-198710000-00008.

81. Peracchia A, Bonavina L. Reoperation after failure of antireflux repairs. Gastroenterol Int 1997;10:S81-S84.

82. Pettersson G, Gatzinsky P. Surgical treatment of symptomatic gastroesophageal reflux recurring after hiatal hernia repair. Acta Chir Scand 1985;151:457-460.

83. Rieger NA, Jamieson GG, Britten-Jones R, Tew S. Reoperation after failed antireflux surgery. Br J Surg 1994;81:1159-1161. doi:10.1002/bjs. 1800810825 .

84. Salminen P, Gullichsen R, Ovaska J. Subjective results and symptomatic outcome after fundoplication revision. Scand J Gastroenterol 2008;43:518-523. doi:10.1080/0036552070178 2019.

85. Serafini FM, Bloomston M, Zervos E, Muench J, Albrink MH, Murr $M$ et al. Laparoscopic revision of failed antireflux operations. J Surg Res 2001;95:13-18. doi:10.1006/jsre.2000. 6015

86. Siewert JR, Isolauri J, Feussner H. Reoperation following failed fundoplication. World J Surg 1989;13:791-796. doi:10.1007/ BF01658439.

87. Skinner DB. Surgical management after failed antireflux operations. World J Surg 1992;16:359-363. doi:10.1007/BF02071549.

88. Szwerc MF, Wiechmann RJ, Maley RH, Santucci TS, Macherey RS, Landreneau RJ. Reoperative laparoscopic antireflux surgery. Surgery 1999;126:723-728. 
89. Zucker K, Peskin GW, Saik RP. Recurrent hiatal hernia repair: A potential surgical dilemma. Arch Surg 1982;117:413-414.

90. Spechler SJ. The management of patients who have "failed" antireflux surgery. Am J Gastroenterol 2004;99:552-561. doi:10.1111/j.1572-0241.2004.04081.x.

91. Scheffer RC, Samsom M, Frakking TG, Smout AJ, Gooszen HG. Long-term effect of fundoplication on motility of the oesophagus and oesophagogastric junction. Br J Surg 2004;91:1466-1472. doi:10.1002/bjs.4759.

92. Galvani C, Fisichella PM, Gorodner MV, Perretta S, Patti MG. Symptoms are a poor indicator of reflux status after fundoplication for gastroesophageal reflux disease: Role of esophageal functions tests. Arch Surg 2003;138:514-518. doi:10.1001/archsurg. 138.5.514.

93. Donkervoort SC, Bais JE, Rijnhart-de JH, Gooszen HG. Impact of anatomical wrap position on the outcome of Nissen fundoplication. Br J Surg 2003;90:854-859. doi:10.1002/ bjs. 4123 .

94. Rijnhart-de Jong HG, Draaisma WA, Smout AJ, Broeders IA, Gooszen HG. The Visick score: A good measure for the overall effect of antireflux surgery? Scand J Gastroenterol 2008;43:787793. doi:10.1080/00365520801935467. 